Archaeological Prospection

Archaeol. Prospect. 23, 105-123 (2016)

Published online 17 November 2015 in Wiley Online Library

(wileyonlinelibrary.com) DOI: 10.1002/arp.1529

\title{
Geophysical and Archaeological Characterization of a Modest Roman Villa: Methodological Considerations about Progressive Feedback Analyses in Sites with Low Geophysical Contrast
}

\author{
ÓSCAR PUEYO ANCHUELA ${ }^{1 *}$, PILAR DIARTE BLASCO $^{2}$, \\ CARLOS GARCÍA BENITO ${ }^{3}$, ANTONIO M. CASAS SAINZ ${ }^{1}$ AND \\ ANDRÉS POCOVÍ JUAN ${ }^{1}$ \\ 1 Departamento de Ciencias de la Tierra, Universidad de Zaragoza, Zaragoza, Spain \\ 2 Escuela Española de Historia y Arqueología (EEHAR-CSIC), Rome, Italy \\ 3 Departamento de Ciencias de la Antigüedad, Universidad de Zaragoza, Zaragoza, Spain
}

\begin{abstract}
The low contrast in physical properties of archaeological elements compared to the host soil is a common drawback in geophysical surveys applied to subtle archaeological sites because those contrasts are usually what are being measured by most instruments. Furthermore, when archaeological elements and construction remains are placed within the same package of materials, differentiation of each can make the interpretation of geophysical data sometimes difficult. In this work we propose a dynamic, integrated approach for the characterization of an archaeological site with simple Roman construction materials in order to evaluate methodological considerations in the evaluation of this kind of sites. This approach includes: (i) a preliminary evaluation of construction material characteristics, according to the background provided by the historical and geographical context and from previous excavations, (ii) measurements of magnetic susceptibility of archaeological and natural materials in the site for direct modelling of the expected anomalies; (iii) a geophysical survey including magnetometry, multifrequency electromagnetic (EM) method and ground penetrating radar (GPR) $(100,250$ and $500 \mathrm{MHz}$ centre frequency antennas); (iv) geophysical data evaluation for planning subsequent systematic surveys; (v) dynamic interpretation of geophysical results through careful data evaluation of all previous steps. The final archaeological model from geophysical data has been successful due to the manner of data interpretation looking for orthogonal patterns of geophysical anomalies that were hypothesized to be subsurface walls. Modelling was then followed by archaeological excavations consisting of three trenches where the walls were exposed. The integration of geophysical data with excavations has permitted to evaluate significance of the different geophysical analysis and to identify their archaeological meaning. The proposed sequential methodology represents an innovative manner of analysis (i) in subtle sites where construction remains are scarce and the absence of well-defined geophysical contrasts can limit the results of usual surveys and (ii) to increase the efficiency in the evaluation of more extensive survey areas. Copyright (C) 2015 John Wiley \& Sons, Ltd.
\end{abstract}

Key words: Roman villa; multidisciplinary approach; geophysical survey; Turiaso

\section{Introduction}

Geophysical analysis has been applied to identify and locate archaeological remains and for the non-invasive characterization of archaeological sites. Geophysical

* Correspondence to: Ó. Pueyo Anchuela. Departamento de Ciencias de la Tierra. Universidad de Zaragoza. C/Pedro Cerbuna, $\mathrm{n}^{\circ} 12$. CP. 50.009. Zaragoza. Spain. E-mail: opueyo@gmail.com techniques, with different success to archaeology, have been widely applied including seismic, magnetic, electric, electromagnetic (EM), gravimetric or ground penetrating radar (GPR) techniques, among others [e.g. Belshe, 1957; Aitken, 1974; Hesse et al., 1986; Scollar, 1962; Linington, 1966; Bevan, 1983; Vaughan, 1986; the updated state of the art can be evaluated in Clark (1996), Gaffney and Gater (2003) and Witten (2006) and references cited therein]. 
Approaches including more than one geophysical technique are also common (Tsokas et al., 1994; Neubauer and Eder-Hinterleitner, 1997; Batayneh et al., 2001; Pellerin, 2002; Seren et al., 2004; Gaffney et al., 2004; Drahor, 2006, 2011; Drahor et al., 2008a; Forte and Pipan, 2008; Bagaloni et al., 2011; Abbas et al., 2012; Apostolopoulos, 2014).

The use of geophysical techniques in archaeology depends upon the site characteristics, time schedule, budget and objectives. The optimal routine is the application of the maximum number of techniques (in order to better characterize the site), with the highest possible resolution and survey density. Some of these factors are not necessarily related to budget or time constraints as the time needed to perform the geophysical survey is usually small compared to most archaeological excavations. In this sense, geophysical surveys are often used as a guide to focus invasive analyses and to define the main target areas.

The application of any one particular geophysical technique can be successful if the contrasts of physical properties of the ground are well known, defined and do not vary appreciably along the surveyed zone (e.g. Hesse, 1999; Ernenwein and Hargrave, 2009). In cases where the targets are known but cannot be defined in terms of geophysical contrasts, the selection of the optimal geophysical technique can be a difficult task. This subject can be addressed considering the historical period and the construction style, but continuous re-evaluation and adaptation of the geophysical survey - including characteristics, processing and interpretation manner - is recommended during the survey design and the geophysical work.

In this work, we present a geophysical survey carried out in a small Roman site (villa) in Tarazona in northeast Spain (Figure 1). The study presented here applies a progressive evaluation of the site characteristics through different research phases, including the selection of geophysical techniques and interpretation manners depending upon the information obtained during the previous phases. The objective was to characterize from a geophysical point of view a site where surficial remnants and preliminary excavations suggested the presence of the villa. The characteristics of the construction materials and the site characteristics showed low geophysical contrasts owing to the low susceptibility contrasts with respect to the host soil and the use of earth materials in the construction. Therefore detailed processing and data interpretation were needed. Here we illustrate the procedures applied for the geophysical characterization of this site that were subsequently compared to excavations. We suggest that our approach that includes multiple sensors, definition of targets and integration with excavations is important especially for geophysical surveys in contexts that have few substantial architectural remains with low contrasts between the host soils and the archaeological elements.

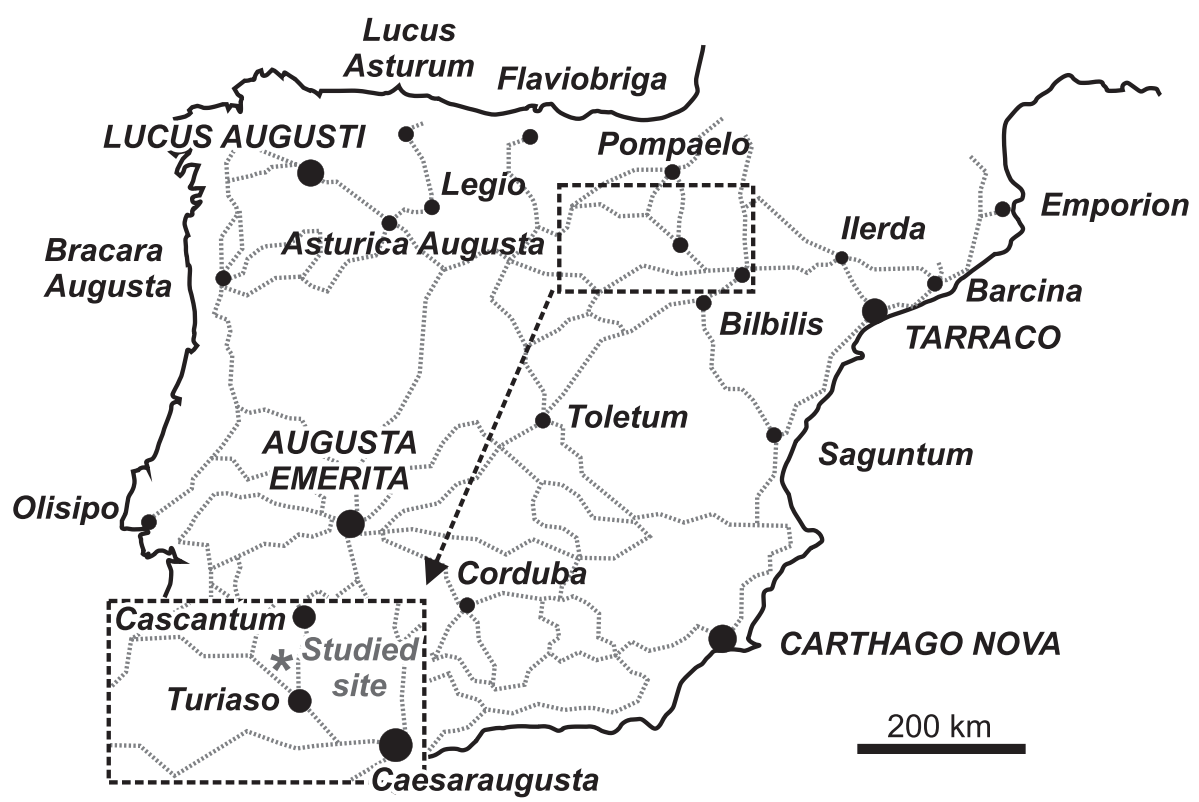

Figure 1. Geographical location of the studied zone with the main roman cities in the Iberian Peninsula. The inset shows the location of Turiaso and the analysed site. 


\section{Historical and archaeological context}

The archaeological site of La Dehesa is located $10 \mathrm{~km}$ north of Tarazona (old Turiaso) and $4 \mathrm{~km}$ west of Cascante (old Cascantum), within the Ebro Basin of northeast Spain (Figure 1), and belonging to the old Roman province of Hispania. The studied site is located at the top of a small hill with bedrock consisting of subhorizontal or slightly sloping units of Cenozoicage rocks composed of detrital deposits and evaporites (Zaragoza Fm., Miocene in age; Quirantes, 1978) (Figure 2a). In the northern portion of the site there are also anthropogenic deposits (Figure $2 b$ ).

It appears the area was inhabited from the Roman period to present, which architecture composed of natural materials such as adobe, rammed earth or fired bricks. Important cities nearby such as Caesaraugusta, Calagurris, Bilbilis, Pompaelo or Ilerda, used opus caementicum, a type of roman concrete, for the construction of the main public and private spaces (Figure 1). However, in rural areas, such as our study site, construction was more commonly with adobe or rammed earth bricks obtained from local sources, in contrast to the monumental and usual buildings in cities, therein the low contrasts between architecture and the surrounding matrix.

The test site is one of the first villae discovered for the archaeological research in the central Ebro Basin. It was discovered in 1979, due to clandestine activities, without an archaeological supervision, which showed numerous Roman remnants (Figure 2c). The site was dated between the first and second century (Bona López et al., 1989; García Serrano, 2003; Sanz Núñez, 1982). After the discovery in 1979, Centro de Estudios Turiasonenses (CET) organized a collection of materials by conducting a small excavation with the participation and assistance of the Provincial Museum of Zaragoza. Clandestine excavations, however, still occurred during the 1980s. Professional activities were again initiated in 2012 when the CET organized a surface survey following an intensive pattern, with straight lines covering the whole area as an attempt to evaluate the areal distribution of the site and to protect its extension that was within farming fields.

On the surface, in addition to some of the identified surficial archaeological remains, a structure $1.5 \mathrm{~m}$ high defines a room excavated in 1979, which is approximately $5 \mathrm{~m}$ wide. Paving placed over an embankment at the north of the site was also identified. Associated with this area Roman pottery remains, tiles, pieces of glass, metal debris and decomposed remains of mortar and adobe were found. The profusion of surface materials and their quality point to a significant centre of activity of the Ager Turiasonense in a portion of the studied site. However, in spite of the importance of this archaeological site that was likely associated with agricultural activities during the early centuries of the roman High Empire (AD 70-192), it is probable that its main buildings were still constructed with adobe or locally derived stone blocks.

The amount and wide distribution of surficial evidences related to ceramics and other elements at the surface supported the hypothesis that a more extensive group of structures remained in the subsurface, whose locations could not be determined from surface observation. Therefore, only geophysical surveys could provide information about the buried structures and other possible features. As the recovered archaeological remains suggested that this site is likely non-monumental, it provided an excellent test for how geophysics, when carefully applied and analysed could be used for the evaluation of sites from more everyday rural life in this area of Spain during the Roman period.

\section{Site characterization, geophysical evalua- tion and targets definition}

The site characterization was performed through (i) an analysis of the historical-archaeological site characteristics (historical, geological and field inspection of construction remains dating of the same period), (ii) a preliminary evaluation in order to define the subsequent geophysical survey (properties contrasts, techniques or needed data distribution), (iii) survey following the interpretations obtained from the preliminary campaigns, (iv) integrated evaluation and geophysical characterization of the archaeological structures in the subsoil, (v) excavation of trenches considering the geophysical data and (vi) re-evaluation of obtained data bearing in mind the results of the archaeological excavation.

Phase 1. Analysis of data and archaeological-geophysical context

Surficial data, accessible outcrops and clandestine excavations in the area permitted us access to information for evaluating the physical characteristics of the site and to predict geophysical contrasts that might produce anomalies in the geophysical surveys (Figure 2). The stratigraphy in the area is composed of (i) near the surface a clay-rich surficial soil unit, ranging in thickness from several centimetres in the northern part of the study area to $1.5 \mathrm{~m}$ in the southern zone, containing small roots, boulders, ceramic fragments and mosaic 


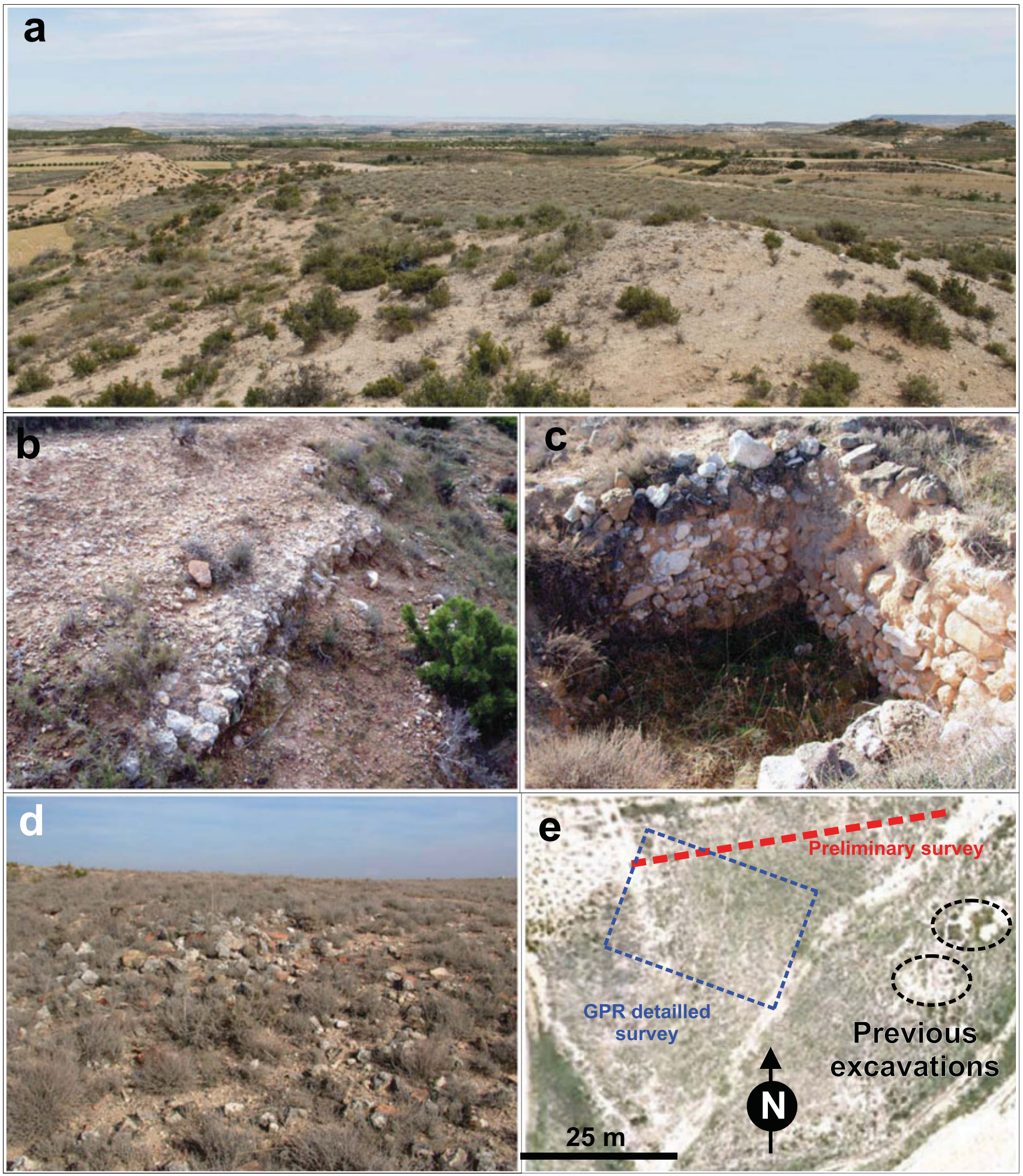

Figure 2. (a) General view of the studied zone and detailed photographs of surficial archaeological remains; (b) archaeological remains along its northern limit; (c) exposed remains in a previous excavation at the site; (d) cluster of boulders with stone blocks and ceramic elements; (e) aerial photograph from the studied site with the location of the preliminary and detailed studied zone; clandestine trenches are also marked. This figure is available in colour online at wileyonlinelibrary.com/journal/arp 
tiles and (ii) underlain by a heterogeneous, grey-yellow unit containing archaeological building debris, coal and ceramic remains (Figure 2d).

The construction materials are composed of adobe, stones and boulders. Walls can be defined by boulders, earth materials, concrete or mortar. In some cases, a pavement between walls is composed of a compact earthen surface with additions of mortar and ceramic fragments. Some of this information on the buried architecture was obtained from previous excavations in the area located to the east of the study area (Figure 2e)

Magnetic susceptibility of soils and architectural materials was easily measured in the field with a hand-held susceptibility meter (KT-10, Terraplus). Mean susceptibility values of various subsurface materials showed differences between groups of materials, and a wide variety of materials from boulders to clay soils, with compacted limes and multi-size particles of anthropogenic fill (Figure 3a). The highest magnetic susceptibility values, which were several orders of magnitude higher than the other analysed materials, were recorded in burned bricks and ceramic fragments. Their influence in the magnetic survey was determined through forward modelling of theoretical magnetic anomalies using susceptibility values measured in the field by 2.5D Gravmag software from the British Geological Survey (Figure 3b). Obtained results indicate that ceramic elements, depending on their depth, produce magnetic anomalies that can reach values between 1 and 3 nT. Boulders, that are usually part of construction elements, only produce significant anomalies when they are close to the surface. The highest value of magnetic anomalies, in the range of several tens of nanotesla, were predicted

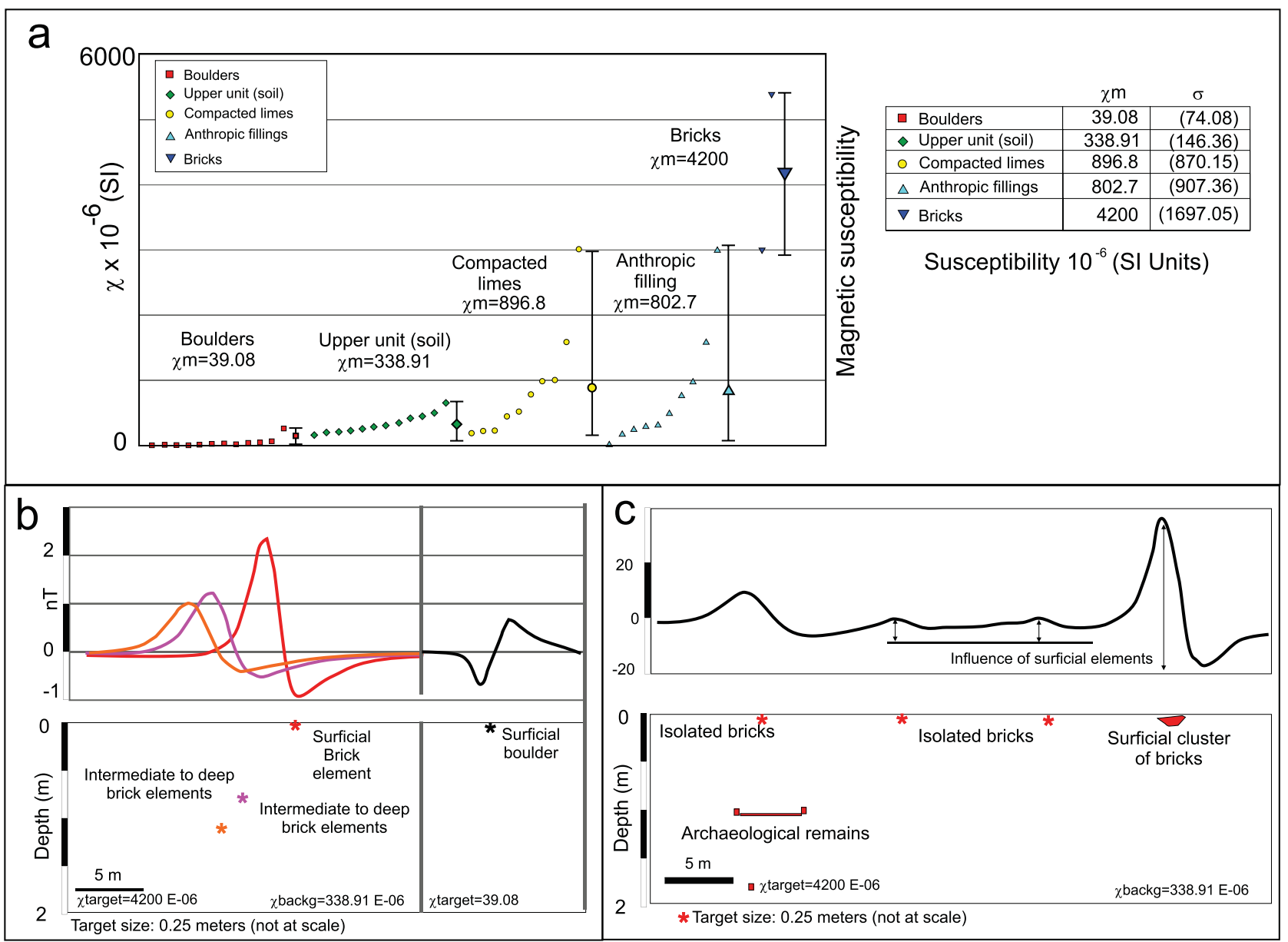

Figure 3. (a) Magnetic susceptibility values measured in the analysed site. Inset shows the table of mean susceptibility values and their standard deviation. (b) Model of anomalies attending different elements related to high susceptibility contrast at different depths or isolated boulders at the surface. (c) Complex magnetic anomalies model considering archaeological construction remains at intermediate depths and analysis of the influence of boulders and archaeological elements at subsuperficial conditions. Mean susceptibility values of elements and background are included in the figure. The size of modelled elements has been increased to help readability; actual size is included in the plots. This figure is available in colour online at wileyonlinelibrary.com/journal/arp 
to be ceramic and brick clusters near to the surface (Figure 3c). These forward models also show that surficial elements not linked to archaeological remains can give similar or even higher anomalies than the buried archaeological structures. The analysis of the magnetic profiles obtained from the anomaly model permitted the identification of various archaeological targets at different depths depending upon the amplitude and wavelength of the magnetic anomalies. These results showed the potentially strong magnetic response of surficial clusters of boulders and the loss of resolution when archaeological structures are located below $1 \mathrm{~m}$ depth.

\section{Phase 2. Preliminary geophysical campaign}

The theoretical predictions and an analysis of presumed buried archaeological targets suggested a very low geophysical contrast in magnetic readings from the buried features. However, magnetometry is a fast survey technique that can be used in order to locate areas to initiate more detailed surveys when magnetic data show even low contrast measurements, as distinct from more homogeneous results. Its effectiveness is noticeable especially where there are concentrations of ceramic elements over and around buried structures, and can therefore be used as an indirect indicator for the location of archaeological remnants. In this sense, and due to the complexity in the evaluation of certain physical properties, a comparative analysis of geophysical data between magnetic and other geophysical techniques was then carried out. The objective of this analysis was to evaluate if there were a correlation between magnetic anomalies that has been considered in the predictive models and other techniques that were then tested in the study area.

The preliminary field surveys consisted of gathering data from each instrument along the same transects using different geophysical devices (Figure 2e): (i) magnetometry [intensity of the total magnetic field and vertical magnetic gradient; GSM-19, Overhauser magnetometer having an incorporated global positioning system (GPS) and two sensors separated $0.5 \mathrm{~m}$ as rover, and a PMG1 proton precession magnetometer as a base]; (ii) electromagnetic multifrequency survey (GEM-02; measurement of three different frequencies: 65, 18 and $5 \mathrm{kHz}$; (iii) GPR with shielded antennas of 100, 250 and $500 \mathrm{MHz}$ (Mala Geoscience, CUI-2). We used the magnetic susceptibility data to evaluate and compare the results obtained from other techniques because no data about the electromagnetic characteristics were available.

Magnetic profiles showed anomalies in the range of 4.6 and $6 \mathrm{nT}$ and maximum vertical magnetic gradients of $6 \mathrm{nT} / \mathrm{m}$ (Figure $4 \mathrm{a}$ ). These values were within the expected range for surficial construction elements
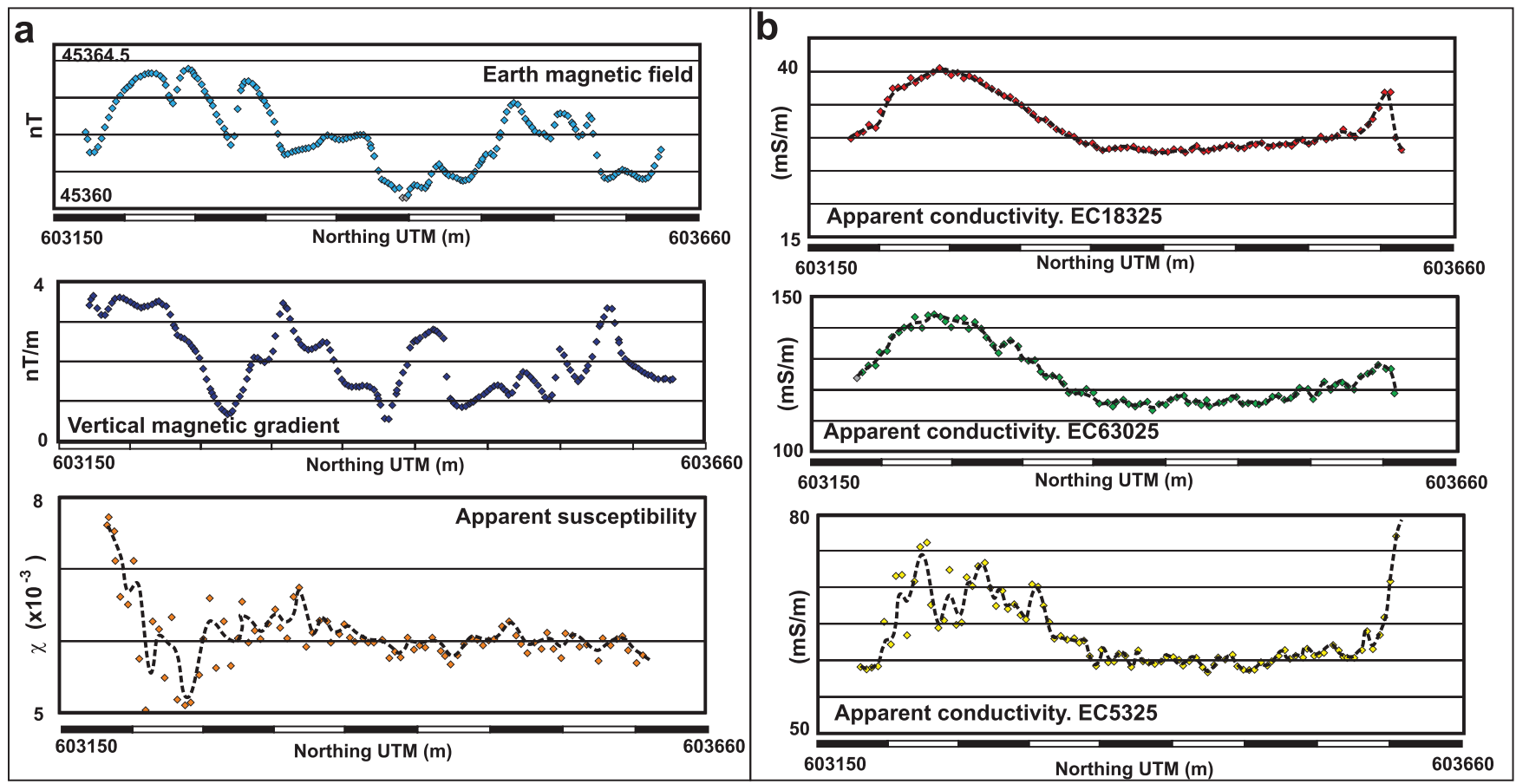

Figure 4. Results from the preliminary campaign along the same profile for magnetic and electromagnetic surveys: (a) magnetic data (intensity of Earth's magnetic field and vertical gradient) and apparent magnetic susceptibility values from GEM-02 device for the $5 \mathrm{kHz}$ frequency; (b) apparent conductivity sections for different frequencies. This figure is available in colour online at wileyonlinelibrary.com/journal/arp 
obtained from the forward models (Figure 4a). EM data were used for the calculation of apparent magnetic susceptibility and electrical conductivity values (Huang and Won, 2000; Huang, 2005). Apparent susceptibility shows mean values of $600 \times 10^{-6}$ (SI units), similar to the values obtained for soils and limes from direct magnetic susceptibility measurements, with slight variations in the range of 50 to $100 \times 10^{-6}$ (SI units), which occurred in the same general areas where magnetic anomalies were identified.

Apparent electrical conductivity shows progressive changes for middle to high frequencies that represents shallow intervals ( 18 and $65 \mathrm{kHz}$; Figure $4 \mathrm{~b}$ ). The highest amplitude variability and the lowest wavelength of anomalies are identified for deeper ground intervals $(5 \mathrm{kHz})$. The anomalies size and the lateral correlation of them through parallel profiles do not show clear map view distributions and they show a wider scattering than susceptibility or magnetic anomalies.

GPR profiles (Figure 5) show a general shallow energy penetration, in the range of $1 \mathrm{~m}$, which was expected from the high apparent surficial electric conductivity identified in the EM survey (between 100 and $150 \mathrm{mS} / \mathrm{m}$; Figure $4 \mathrm{~b}$ ). There was no difference in energy penetration depths between the 100 and $250 \mathrm{MHz}$ antennas due to this attenuation of energy at about $1 \mathrm{~m}$ depth (Conyers, 2013). The energy penetration of $500 \mathrm{MHz}$ antenna was significantly lower, with energy reaching just a few decimetres. Hyperbolic reflection features are better defined in the $500 \mathrm{MHz}$ profiles. In general, reflection features visible in GPR profiles are coincident between profiles (Figure 5), suggesting linear alignments in the ground. The analysis of GPR profiles permitted the identification of buried features composed of homogeneous materials, which varied in appearance depending on the antenna used. The analysis of GPR profiles should present a homogeneous, parallel and horizontal banded distribution of reflectors if underground is homogeneous. In this sense, an analysis of such changes that modify the expected homogeneous underground structure was carried out. In these analysis interruptions of the horizontal homogeneous underground structure identified at $100 \mathrm{MHz}$ profiles, not horizontal reflectors at 100 and $250 \mathrm{MHz}$ and hyperbolic anomalies at 250 and $500 \mathrm{MHz}$ were considered. Changes in the definition of reflectors and their continuity and reflectivity were considerable between parallel profiles, indicating the complex nature of buried walls in the study area.

The previously described variations in the GPR profiles were then compared to magnetic and EM data along coincident profiles. Magnetic anomalies are characterized by dipoles and were mapped in the study area as positive or negative residuals. Both normal and inverse dipoles generally coincide with the hyperbolic-shaped GPR reflections, and are interpreted to be buried architectural features composed of slightly magnetic materials (Figure 5). These changes, subvertical interruptions of the underground structure, dipoles and hyperbolic-shaped reflection features are distinct from areas where the ground is homogeneous. In the case of EM data, anomalies show in general only small changes in amplitude and longer wavelengths than the other techniques. This comparison suggests a lower sensitivity and resolution of EM data compared to the other techniques.

The interpretation and evaluation of the preliminary campaign results permitted us to establish some general guidelines for the subsequent systematic surveys. These considerations pointed to the target definition, the survey distribution and the expected resolutions that can be obtained depending upon the employed techniques and the obtained results of anomalies sizes and contrasts. Since EM anomalies do not show the expected pattern for archaeological remains, it was not used in the subsequent survey. However, magnetic anomalies are small in size and in the expected range for the size of buried archaeological remains. Moreover the identification of homogeneous magnetic domains (in trend or in values) between alignments of anomalies recommended the use of magnetic survey in the detailed campaign. Magnetometry was therefore used for the overall survey as it provided a systematic and fast characterization of the ground. These results then were used to define and focus on areas for more detailed analysis by GPR. Each technique has different objectives: (i) magnetic areal survey, in order to locate sectors where changes in the earth magnetic field were identified and (ii) GPR survey with high density sampling following parallel profiles in two normal directions in magnetically heterogeneous sectors. This approach was considered as it allowed for the analysis of an extensive area and was then used to focus subsequent analysis with GPR in selected zones.

\section{Magnetic areal survey}

The magnetometry surveys covered $6000 \mathrm{~m}^{2}$ with 9000 measurement points collected of intensity and vertical gradient taken along profiles having different orientations. At least, one measurement point every square metre was collected. In advance of the survey, boulders and the larger ceramics where picked up from the surface to avoid their potential influence to 


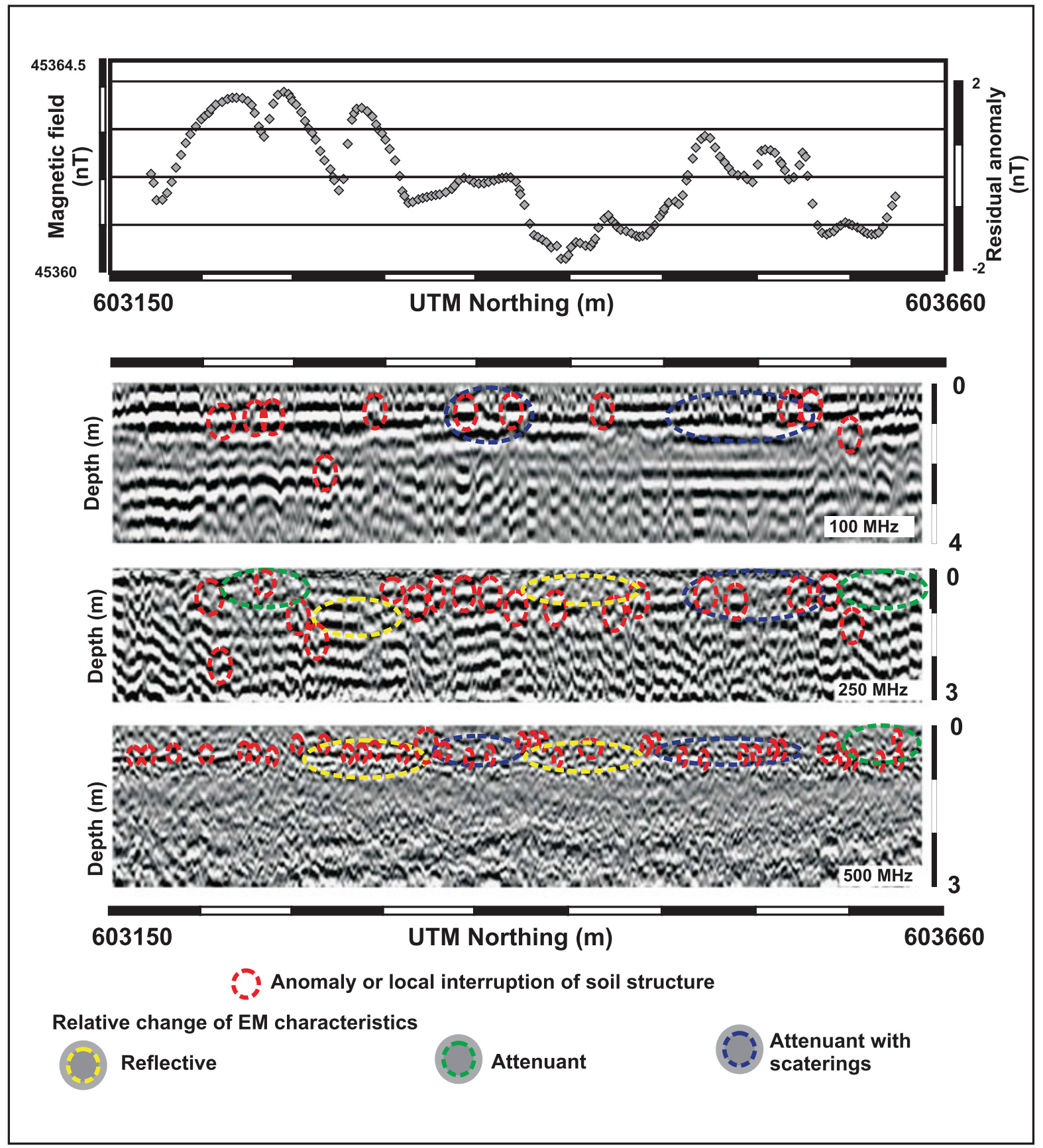

Figure 5. Comparison of magnetic field data and the ground penetrating radar (GPR) profiles for 100, 250 and $500 \mathrm{MHz}$. The main changes identified in the GPR profiles are highlighted. This figure is available in colour online at wileyonlinelibrary.com/journal/arp

the survey. The data was collected using a magnetometer with GPS that permitted the locations of all readings. Magnetic data processing consisted of diurnal variation corrections, filtering of data with low measurement definition and exclusion of anomalously high values prior to data interpolation and gridding. Magnetic anomalies in the raw data are on the range of $20 \mathrm{nT}$ with the highest values associated with surficial clusters of boulders and larger ceramic fragments, especially prevalent in the northwest sector of the survey area. These clusters are likely related to previous farming activities where these materials were removed from fields in recent times.

Outside these anomalously high magnetic sectors, the range of variation of the magnetic field is $10 \mathrm{nT}$ and anomalies usually do not exceed $2 \mathrm{nT}$. The 
vertical magnetic gradient map does not show continuous anomalies, whereas the total magnetic field shows groups of anomalies with E-W and NW-SE main orientations (Figure 6). This distribution of magnetic anomalies along linear trends can be interpreted in terms of anthropic modifications of the underground subsoil structure. The most significant change in the earth magnetic field survey is the identification of a sector with higher magnetic field intensity (marked sector in Figure 6b) and alignments of magnetic dipoles. This is the sector that was selected for GPR survey because it included not expected natural magnetic anomalies alignments and sectors with higher intensity of magnetic data laterally limited by dipoles alignments.

\section{GPR survey}

A $30 \mathrm{~m} \times 20 \mathrm{~m}$ grid was established in an area where several magnetic anomalies were mapped (Figure 6b). Both 250 and $500 \mathrm{MHz}$ antennas were used with a grid of profiles in two orthogonal directions. Profile separation was $1 \mathrm{~m}$ with 80 total profiles. Traces were collected at regular measurement intervals between 1 $(500 \mathrm{MHz})$ and $3 \mathrm{~cm}(250 \mathrm{MHz})$ and defined by 1024 samples per trace. The survey was carried out with
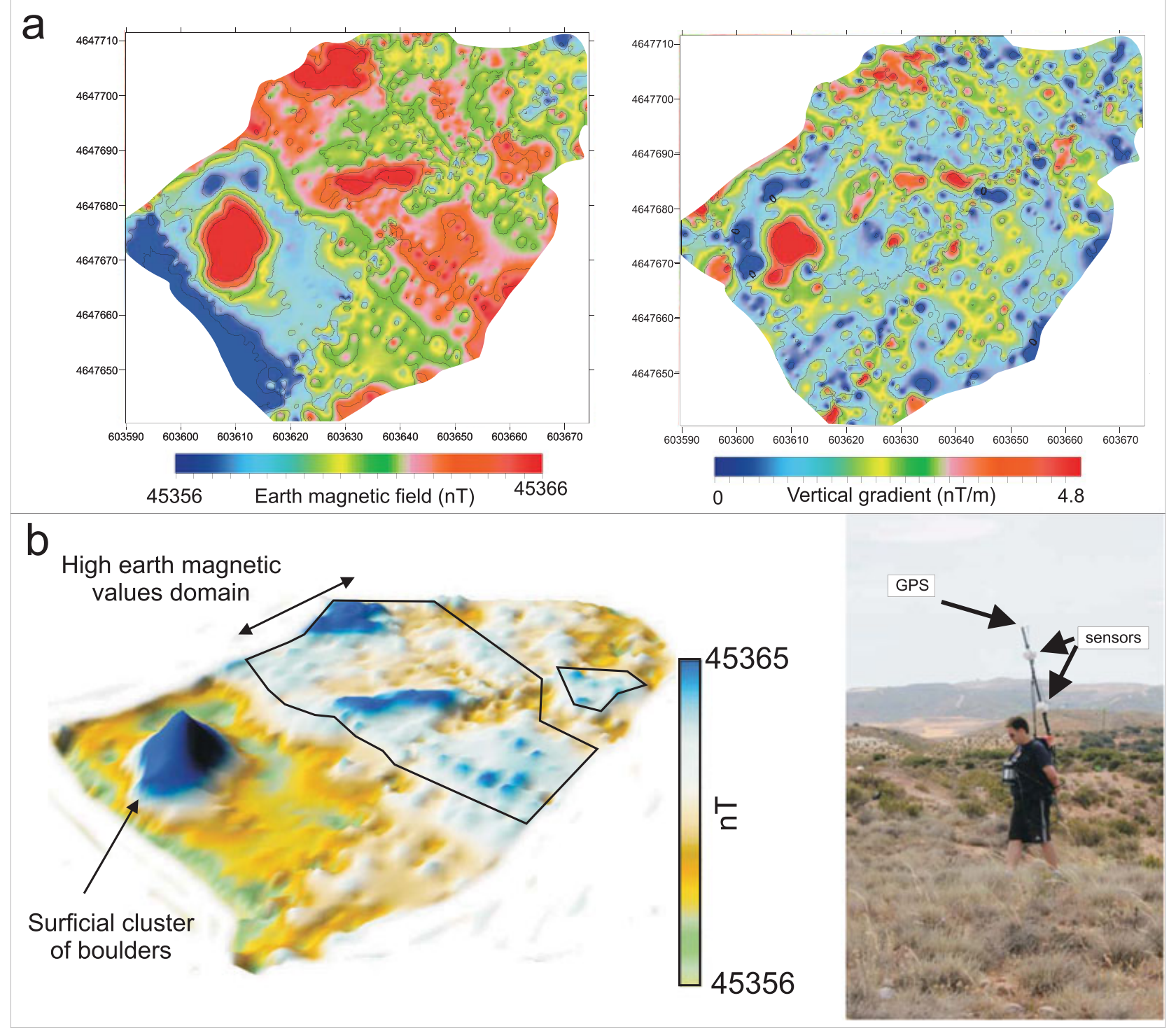

Figure 6. (a) Areal survey for vertical magnetic gradient and magnetic field along the surveyed area. (b) Presentation in false relief of data obtained from intensity of magnetic field and area delimited by alignments of anomalies. This figure is available in colour online at wileyonlinelibrary.com/ journal/arp 
an odometer (survey wheel) attached to the antennas. Reflection processing consisted in zero time correction, amplitude gain (linear and exponential), band-pass filtering for the removal of noise at both the high and low range of the amplitude spectrums of each antenna, running averaging of traces to reduce random noise, and background removal.

Data interpretation consisted of manual picking of areas where there were changes in reflectivity, attenuation, clear reflectors, lateral interruption of reflectors and hyperbolic anomalies. The identified reflections, which were mostly hyperbolic reflections from pointsources were then plotted to view their distribution.
This map showed sectors with clusters of hyperbolic reflections and also lateral interrupted planar reflections, all of these, suggests buried walls and perhaps floors or cut and fill anthropogenic features.

Changes between reflective and attenuating media and the presence of hyperbolic reflections are suitable for semi-quantitative analysis and amplitude maps were then constructed (Conyers, 2013). These amplitude slicemaps permitted the identification of sectors with high reflectivity and also zones of high density of hyperbolic reflections (Figure 7a). Amplitude slices were constructed from 5 to $25 \mathrm{~ns}$ depth $(10 \mathrm{~cm}$ to $1.3 \mathrm{~m})$. The mapped distribution of changes in reflectivity did not

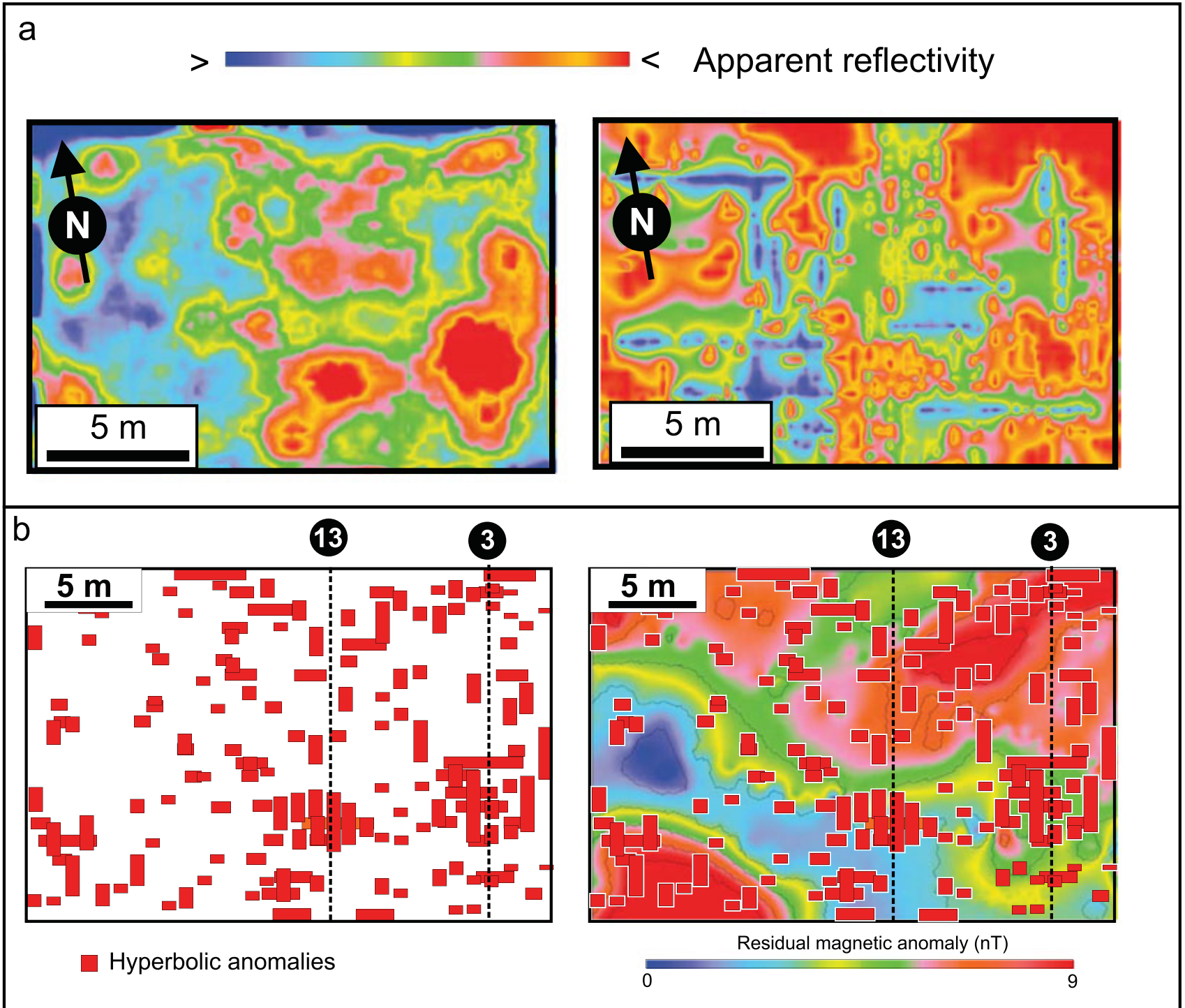

Figure 7. (a) Apparent reflectivity maps for ground penetrating radar (GPR) data with different interpolation distances. The TWT selected interval represents the equivalent to $1 \mathrm{~m}$ depth and the TWT interval for deeper conditions than the location of anomalies (over $1.5 \mathrm{~m}$ ). (b) Cartography of hyperbolic anomalies and superposition on magnetic data. In both figures the profiles analysed in Figure 8 are marked. This figure is available in colour online at wileyonlinelibrary.com/journal/arp 
show an ordered distribution of changes that was expected for archaeological buried structures.

The comparison of these GPR slice-maps (Figure 7a) show that higher reflective media and the visual identification of concentrated hyperbolic-shaped point source reflections correlates with the middle to high values of the magnetic field and the clustering of magnetic dipoles. There are still some clusters of hyperbolic GPR reflections that coincide with low values of the magnetic field (Figures 5 and $7 \mathrm{~b}$ ). This is interesting as it appears to show that the use of multiple sensors here can not only identify the buried architecture but also identify its composition. The forward models suggest that areas of adobe architecture will have low magnetic contrasts, but will still generate GPR reflection hyperbolas. Those composed of more magnetic materials such as burned bricks or boulders will look similar in GPR profiles and amplitude maps, and also have a higher magnetic contrast. When viewed in cross-section, these differences can be readily identified (Figures $8 \mathrm{a}$ and $8 \mathrm{~b}$ ).

These results permitted us to define, from a geophysical point of view, (i) areas where there are changes of the structure of subsoil materials that have archaeological significance, and (ii) homogeneous and heterogeneous areas that are more likely inter-feature areas.

\section{Interpretation and discussion}

\section{Construction of anomalies models with archaeological relevance}

Different geophysical approaches are usually employed for the characterization of archaeological remains with different success. Magnetometry has shown a wide application in archaeology, especially for the identification of archaeological elements with high susceptibility contrasts, usually related to artificial, buried objects, burnt features and rubbish deposits. Magnetic anomalies in archaeological sites usually exceed in amplitude the anomalies identified in this work and they are related to artificial elements in graves (10-20 nT; e.g. Özgü Arısoy et al., 2007), bricks and metal deposits within the archaeological structures (Drahor et al., 2008b), burnt features and rubbish deposits (10-15 nT; Gaffney and Gater, 2003), pottery kilns (Tsokas and Hansen; 2000), pithouses (reaching 50 and over $1000 \mathrm{nT}$, Eppelbaum et al., 2010; Rogers et al., 2011; Argote et al., 2000), storage pits (e.g. Rego and Cegielski, 2014; with anomalies between 10 and $14 \mathrm{nT}$ ) or monumental structures of large scale (e.g. Caggiani et al., 2012; with more than $50 \mathrm{nT}$ of variation range).
In general, the distribution of magnetic anomalies in map view does not define a three-dimensional (3D) construction pattern except when these anomalies are linked to monuments, present a well defined susceptibility contrast with respect to the host soil or when there are no construction elements dispersed around constructions. In many cases, anomalies related to buried buildings are determined by the clustering of high susceptibility elements that are contained within, or surrounding, archaeological structures. When adobe structures or local natural materials are used for construction, as the presented case, they define subtle anomalies that can be difficult to isolate from the host soil. Moreover, the presence of collapsed walls and buildings and the subsequent farming activity can significantly challenge the interpretation and data processing in this kind of site. For this case, long-wavelength anomalies and zones where magnetic anomalies cluster can be used as an indirect indicator of heterogeneous, non-natural domains.

The use of resistivity or EM methods, excluding GPR, has also permitted the characterization of archaeological features but, in general, with long wavelengths or low resolution results. These data have been used for the location of non-natural subsoil structures, the evaluation of areas suitable for applying other geophysical techniques or direct excavation. In some cases wide anomalies have been identified over archaeological buried structures (Witten et al., 2000; Urban et al., 2014) or decametric structures (Drahor et al., 2008a; De Smedt et al., 2013, 2014; Zheng et al., 2013). In these works similar conclusions to the presented EM survey were obtained, reducing its applicability due to resolution requirements and the particular site characteristics.

In the case of GPR, clear ordered patterns of reflectivity anomalies have been obtained in cases where archaeological structures are located within a homogeneous soil or where there are no collapsed structures or boulders disseminated between the archaeological structures (e.g. Conyers, 2004, 2012, 2013). In other cases, changes in the reflectivity or clusters of anomalies have been used in order to define monumental structures (e.g. Papadopoulos et al., 2002), or, at an intermediate scale, the potential presence of archaeological features can be detected through amplitude grid maps (e.g. Lasaponara et al., 2014). With independence of these aspects, even in cases of adobe constructions, GPR anomalies are expected (e.g. Sternberg and McGill, 1995).

Integrated geophysical multi-technique analysis has been employed to achieve more robust interpretations or to determine the origin of anomalies by feedback analysis. The analysis of previous works in this subject 


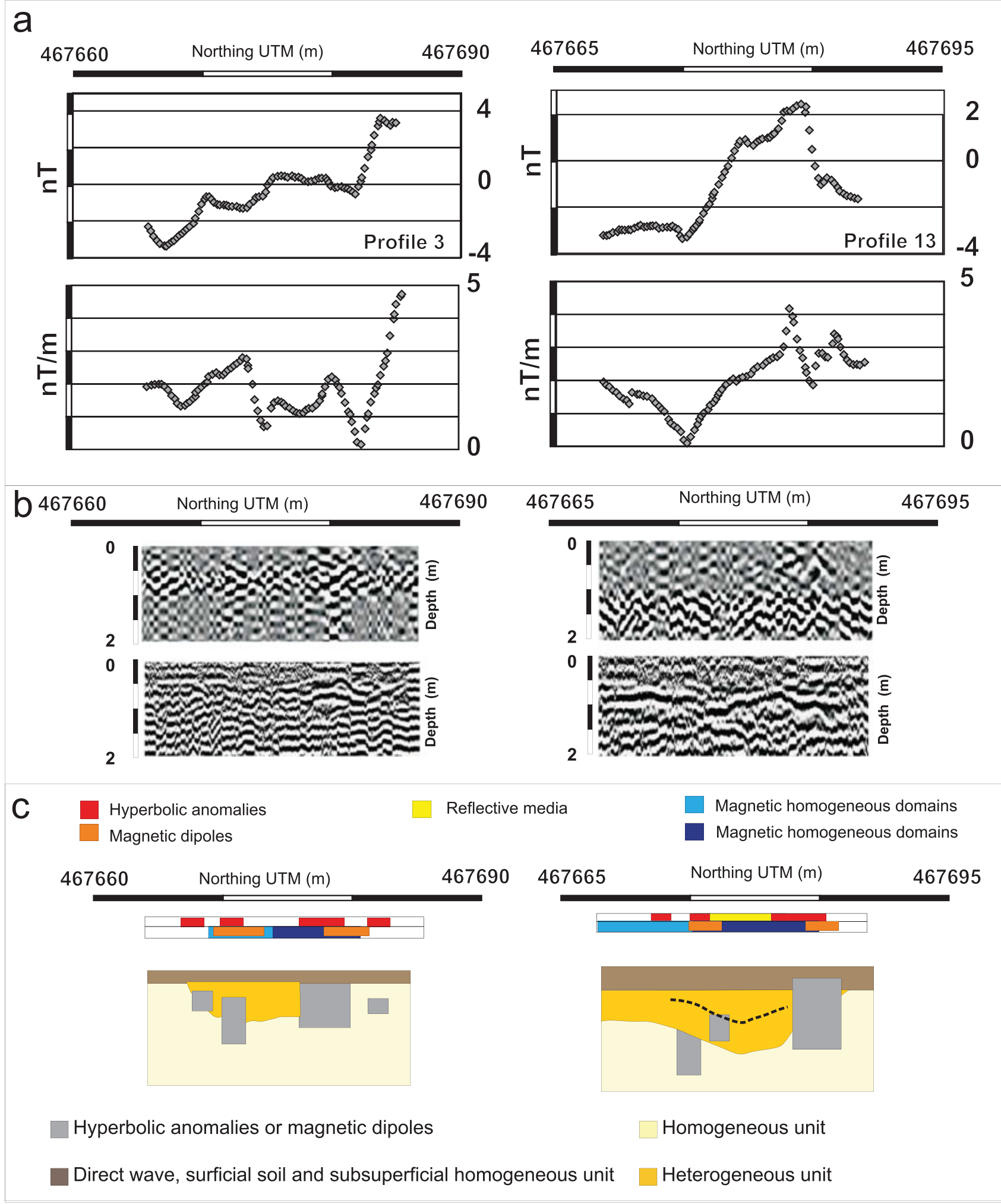

Figure 8. Example of comparative analysis along two selected transects whose location is shown in Figure 7b. (a) Earth's magnetic field and vertical gradient anomalies. (b) GPR profiles coincident with profiles in (a); the profiles are included after background removal (upper) and overgained. (b), (c) Comparison of anomalies in the different techniques attending the location of magnetic dipoles, homogeneous trends at magnetic field intensity and vertical gradient, hyperbolic anomalies and reflectivity/attenuation changes in the profiles. Conceptual models along two-dimensional (2D) sections integrating the geophysical results are also included. This figure is available in colour online at wileyonlinelibrary.com/journal/arp 
shows that results are, in many cases, site-dependent. Different correlations have been proposed between the results of geophysical techniques and archaeological structures, showing (i) wide EM anomalies, but not significant magnetic or GPR anomalies (Witten et al., 2003) over construction elements, (ii) electrical resistivity tomography (ERT) anomalies related to walls and high overprint on these structures of high susceptibility elements in the magnetic data (Drahor et al., 2008a) or (iii) GPR and magnetic data correlations without clear patterns in map view distribution (Lasaponara et al., 2014). With independence of these limitations, for certain cases where techniques and the terrain characteristics are suitable, some considerations about the urban construction style and map view distribution can be found integrating different techniques (e.g. Shaaban and Shaaban, 2001; with ERT and GPR).

In the presented case, although there are not clear patterns of distribution of geophysical anomalies, a direct correlation between the different geophysical results has been obtained. This correlation reveals that GPR and magnetometry are sensitive to changes in the subsoil structure, although anomalies cannot be univocally related to archaeological building remains. In order to decipher the origin of these anomalies and their potential correlation with archaeological structures, some methodological considerations were established, following the available archaeological and historical information: (i) the identified anomalies are associated with objects that are included within the soil and can be related to structures, either in situ or displaced from their original position; (ii) the identification of homogeneous trends in magnetic anomalies or reflective sectors at the GPR can be related to pavements or anthropogenic levels; (iii) the clustering of anomalies reveals the proximity to structures, not necessarily in situ; (iv) at least three anomalies located along a straight line can be used as an indicator of a linear structure (two of them located in two adjacent profiles).

These rules were used for data reinterpretation and the construction of an archaeological model for geophysical data. In a first step, at the coincident area surveyed by magnetics and GPR, homogeneous and heterogeneous domains in the subsoil were mapped. This analysis consisted in the correlation between sectors having reflective or attenuated media in the GPR and where magnetic field and vertical gradient show homogeneous trends. This analysis was done defining sectors for each technique and analysing their overlapping. The limits between these domains were established by the behaviour change and, in some cases, following alignments of hyperbolic anomalies or magnetic dipoles. This approach excludes elements that produce isolated anomalies without direct correlation between parallel profiles. An example of step-by-step procedure is included in Figure 9. In Figure 9a the distribution of anomalies identified at GPR (mainly hyperbolic anomalies but also the lateral distribution of reflective media in the subsoil) has been included. In this plot GPR anomalies are distributed along the study area without a clear pattern. If magnetic anomalies are considered along a selected profile (Figure 9b) a correlation with GPR hyperbolic anomalies is identified. This correlation was also evident in the preliminary survey. From a conceptual point of view, walls can be interpreted in cases where correlation of hyperbolic anomalies along GPR profiles is possible and only when they show a parallel distribution in magnetic susceptibility changes. The integrated analysis permitted to separate homogeneous and heterogeneous domains in terms of GPR and magnetic data. This evaluation permits to exclude anomalies that can be related to isolated blocks or clusters of blocks around collapsed buildings, or resulting from farming activities. Therefore, some anomalies can be interpreted in terms of walls or archaeological remnants (Figure 9c) against other anomalies that show a geophysical record not consistent with in situ archaeological structures. A more detailed sketch of the evaluated factors to distinguish archaeological structures in each of the identified anomalies and their correlation is included in Figure 9d.

The map distribution of anomalies (magnetic survey) or amplitudes (GPR) did not permit to identify a clear pattern of archaeological structures. However, the profile evaluation permitted to identify homogeneous magnetic domains laterally delimited by alignment of anomalies (dipoles or hyperbolas). This evaluation permitted to exclude anomalies from the studied zone that do not have a direct correlation to structures and the distribution of anomalies following the described approach showed along the studied zone an ordered distribution.

Interpretation following a visual inspection of homogeneous and heterogeneous domains, and later the evaluation of lateral correlation of anomalies has permitted to interpret the anthropogenic, archaeological underground structure. In the case of the GPR, buried structures have only been interpreted when a straight correlation between, at least, three anomalies in three different parallel profiles were found. Homogeneous magnetic domains or sectors with homogeneous attenuating or reflective media in GPR profiles and delimited by linear structures, were interpreted as spaces between archaeological structures. In this 


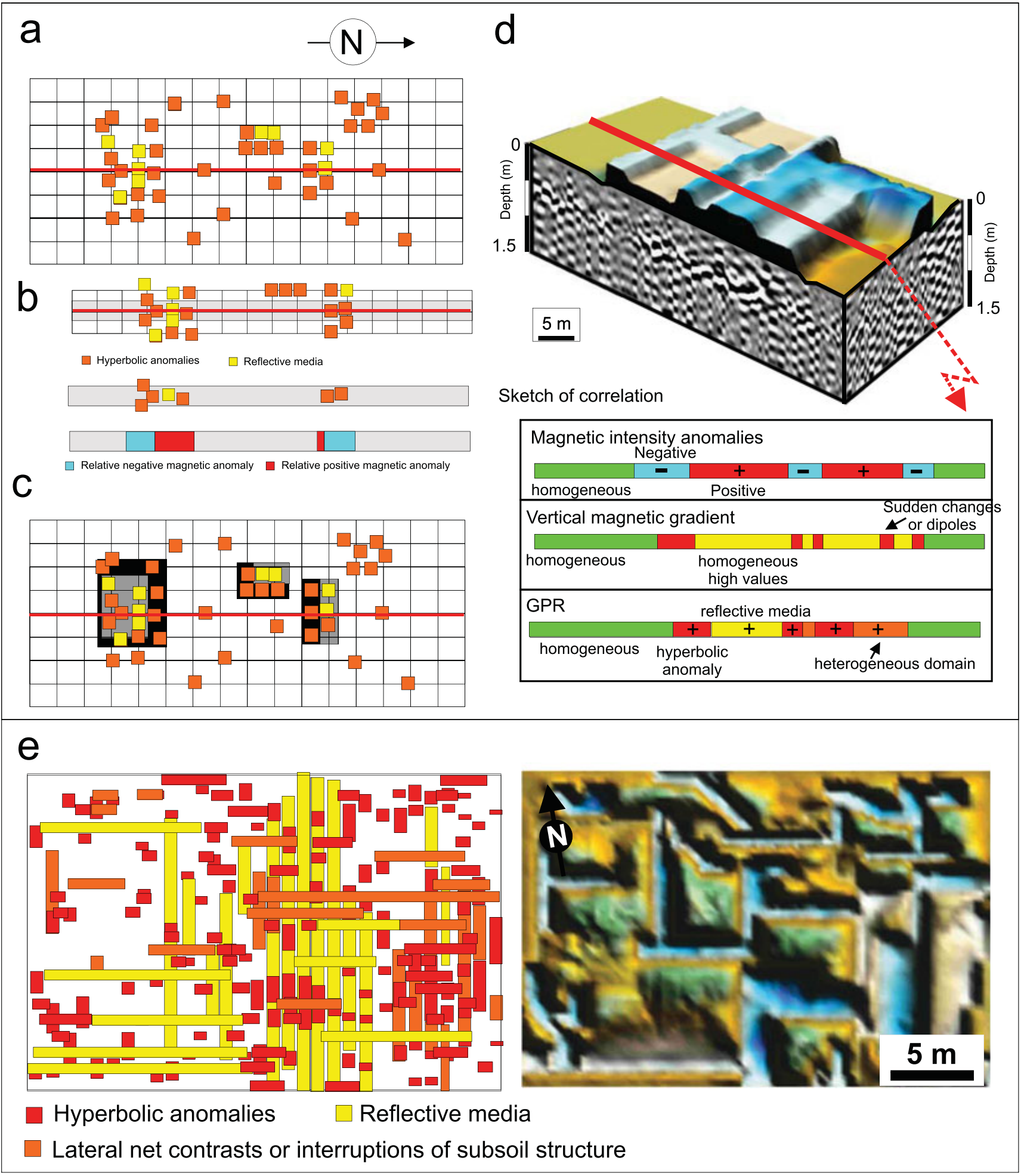

Figure 9. Applied methodology in the evaluation of correlation of anomalies obtained from the different geophysical techniques. Conceptual model of interpolation manner: (a) distribution of anomalies; (b) evaluation of lateral correlation of anomalies considering changes in magnetic field and vertical gradient in homogeneous and heterogeneous domains; (c) interpretation of domains and model evaluation of archaeological remains. (d) An example of integration of GPR data, model construction of anomalies and correlation with changes in Earth's magnetic field and vertical magnetic gradient is included. (e) Distribution of GPR changes along the studied zone that has been used in order to evaluate direct correlation of anomalies by means of magnetic data. False relief image of the model obtained from interpolation of anomalies through the integrated analysis exemplified in (a) and following the proposed methodology. This figure is available in colour online at wileyonlinelibrary.com/journal/arp 
model, anomalies that do not follow the previously defined rules were not considered in the construction of the geophysical model. This model permitted to identify an ordered pattern of anomalies with the expected geometry for buried archaeological structures (Figure 9b).

\section{Analysis of the significance of the model of anomalies}

The proposed model of correlation of anomalies can be interpreted in terms of archaeological structures and pavements between them. This approach permitted the identification of ordered patterns of elements that were not identified or were difficult to analyse from a direct data analysis without a manual, detailed interpretation. However, this kind of analysis, which conceptually can be of application and can be successful, cannot be validated without comparison with direct excavations.

During 2012, a partial archaeological excavation campaign was carried out along representative domains of the geophysical model and also exceeding the anomaly distribution to define if the homogeneous trends between anomalies could be related to natural soils or areas without clear archaeological structures. Three trenches were dug in order to characterize sectors where alignments of anomalies intersect (Figures 10a and $10 \mathrm{~b}$ ). In the three excavations construction remains were found. These remains are two cistern with probable industrial use and a third one, whose utility could not be defined. It was surprising to find these industrial remains in a sector where structures for domestic use were previously found (block found in 1979, remains of a large pavement to the north of the archaeological site and domestic potteries). All in all, the correlation between the geophysical results and the archaeological remains was confirmed (Figure 10c).

In trench C (Figure 10d) a group of decimetric walls composed of natural boulders with mortar and tesselae was found. The space between walls, that has not a clear functional attribution, presents a heterogeneous structure with construction elements, adobe bricks and mortar fragments. The geophysical model for this sector showed small hyperbolic anomalies with reflective media and a heterogeneous sector between the alignments of hyperbolic anomalies. This can be interpreted as the filling of the space between walls by inward collapse. Magnetic susceptibility of analysed materials shows low to intermediate values of susceptibility, similar to that identified for boulders and soils, with heterogeneous values for the mortar levels. The intensity of magnetic field for this area showed intermediate to high values, especially in correlation to hyperbolic anomalies and reflective media.
Trench D (Figure 10e) was located in a well defined alignment of small anomalies within a heterogeneous domain. The space between these alignments presented homogeneous vertical magnetic gradient values and low intensity of magnetic field. The excavation showed three walls forming a U-shaped structure, composed of different construction styles and made of concrete, mortar as cement, rocks and ceramic fragments. Between the walls, a pavement and a high concentration of boulders, adobe bricks and mortar fragments were identified. The pavement is composed of mortar, sand and small rock fragments. In contrast with the previously described trench, the geophysical model did not permit to isolate the different walls identified in the trenches. This sector showed a homogeneous signature in magnetometry and a heterogeneous GPR-domain limited laterally by alignments of anomalies. Geophysical data did not permit to identify the exact origin of the different isolated elements, and it was considered as related to an anthropic structure. Excavation of this element showed a small industrial pool defined by construction walls and an anthropic pavement between them.

Two orthogonal walls were identified in trench E (Figure 10f), which can be interpreted as part of a pool for industrial purposes of hydraulic character. The construction characteristics for walls and soil are similar to trench D. Geophysical data permitted to identify a wide archaeological structure confirmed as walls with two normal directions and a pavement between them. As in the case of trench D, the susceptibility measurements in the excavation show middle to low values, in the range of the measured soils. Mortar showed slightly lower susceptibility values but within a very variable range. Magnetic data show small dipoles of magnetic vertical gradient at the limits of the structure, homogeneous trends between them, and lower values for the total magnetic field for the inner area with respect to its surroundings. The geometry of the archaeological remains was drawn from the geophysical model, although the marginal walls were not clearly defined as isolated structures.

\section{Considerations about the applied methodology}

As previously stated, geophysics has been usually employed in archaeological characterization and it represents invaluable information for subsequent archaeological excavation. However, local archaeological characteristics and construction style can limit the potential geophysical results or make difficult their interpretation.

The use of adobe structures and local rocks for urban construction is common in the Central Ebro Basin but 


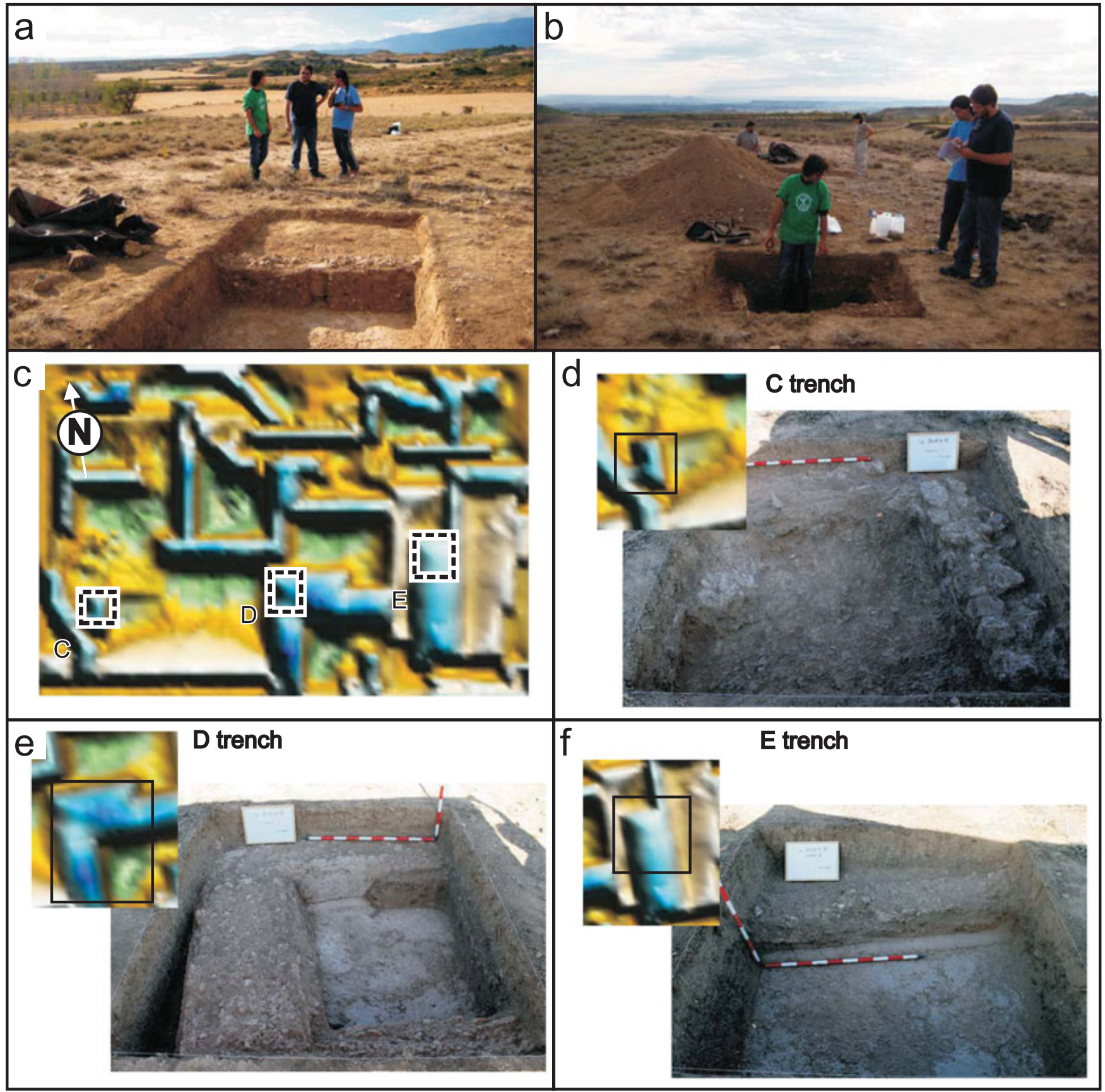

Figure 10. (a), (b) Photographs of the excavation campaign. (c) Location of sectors excavated in order to constrain the geophysical model. In each of the trenches, a photograph from the excavation and the geophysical model is included. (d) Trench C. (e) Trench D. (f) Trench E. This figure is available in colour online at wileyonlinelibrary.com/journal/arp

also in buildings that do not represent a monumental development or do not have social or cultural uses. The comprehension and research of this kind of structures can be of higher interest than monumental structures because they are more sensitive and representative of the life style. However, this kind of interesting research subjects present identification problems both for traditional archaeological and geophysical research.
In this work, an approach that can be of wide interest and applicability in this kind of complex contexts has been carried out. In the analysed case, low relevance constructions, scarce remains and low geophysical contrasts define the archaeological site. Traditional manners of interpretation of anomalies has not permitted the site characterization due to the presence of elements with similar or higher 
geophysical contrast than those related to the buried archaeological structures. The proposed approach through the definition of some rules has permitted to define a walkthrough interpretation of anomalies with archaeological relevance.

The proposed routine has been applied following a progressive definition of targets, objectives, contrasts, techniques and methodologies (Figure 11) that are shared in many research projects. The different research phases can be grouped into a 'preliminary phase' when the site can be evaluated from local or regional information. This first phase permits to constrain the methodologies or approaches to be applied. The second phase includes the 'site analysis and survey design' considering (i) geophysical noises, (ii) extension of the site, and (iii) surficial analysis to evaluate the expected contrasts of properties between archaeological features and the natural terrain. These data can permit to delineate a first geophysical campaign where resolution, discrimination availability, amplitude and wavelength of anomalies for different techniques can be evaluated. This evaluation should permit the geophysical design in terms of resolution and data density.
However, usual processing and presentation procedures did not permit to identify the archaeological remains in the subsoil. In this case, we propose a 'more detailed data interpretation' stage, following the discrimination of sectors with high density of anomalies that can be related to archaeological structures themselves or to the urban design. In this phase, manual separation of in situ archaeological elements and displaced or natural elements was based on their lateral correlation in parallel profiles. After this evaluation, a map view or anomalies model distribution can be double checked with excavation. This comparison is the stage of 'feedback evaluation with the previous geophysical model', aimed at modifying or validating the geophysical interpretation.

The limited contrasts between host rock and buried archaeological remains and the distribution of debris are usually a threshold for geophysics in this kind of site. Magnetic anomalies do not allow unequivocal interpretations because of the low contrasts between natural materials and archaeological remains, the different signature of archaeological features (with both low and high susceptibilities), the strong imprint

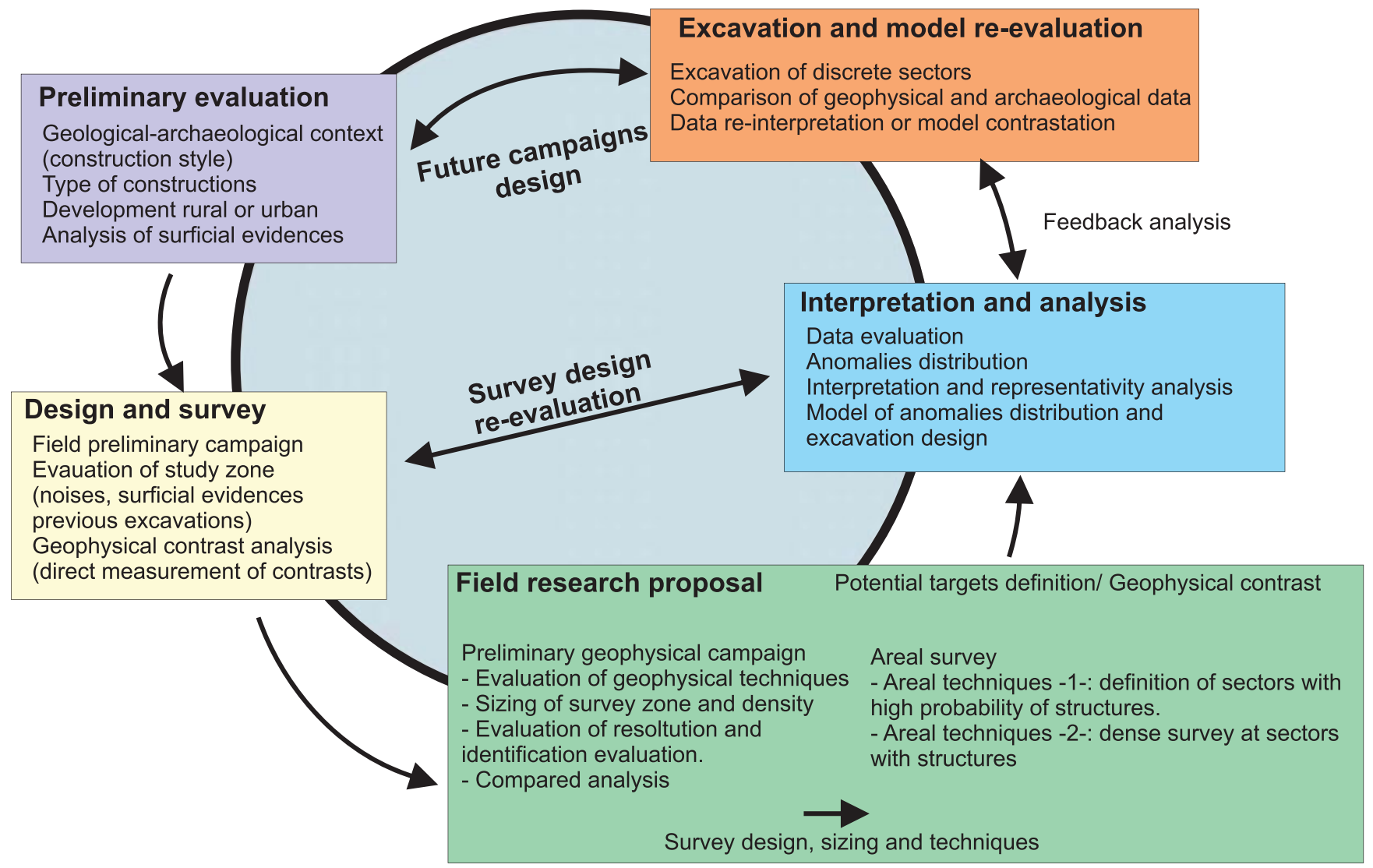

Figure 11. Research phases carried out along the presented study, their interaction and back steps. This figure is available in colour online at wileyonlinelibrary.com/journal/arp 
of ceramic elements in magnetic data and the presence of construction elements without direct connection with structures. These factors have limited the preliminary direct reconstruction of the archaeological structure from magnetic data, map distribution of hyperbolic anomalies or amplitude grid maps. Therefore, a detailed analysis is necessary to differentiate between in situ and displaced archaeological remains and to identify ordered anomaly patterns with independence of their geophysical signature. In this sense, data reinterpretation in terms of lateral continuity of anomalies, with independence of their signature, is a correct approach in order to delineate the buried structure of the archaeological site.

\section{Conclusions}

The integrated analysis of La Dehesa site in Tarazona (northeast Spain), including geophysical analysis in different steps, and excavation, has permitted to evaluate the success of integrated analysis at a roman villa. These archaeological sites do not contain significant architectural elements and the construction materials do not present properties significantly different with respect to the natural materials. Our analysis has considered a preliminary target definition where small contrasts between archaeological remains and the host soil have been identified. Different geophysical signatures depending upon the construction materials (adobe bricks, stone blocks and mortars) produced both positive and negative magnetic anomalies. The distribution of these elements both in situ and displaced from their original position and the dispersion at the surface of high susceptibility elements (ceramics) precluded the identification of an ordered pattern of anomalies at a preliminary interpretation stage.

GPR and magnetic techniques show congruent results, although they do not permit to obtain a simple or direct picture of the archaeological features. Nevertheless, feedback analysis and continuous re-evaluation of geophysical data and comparison with previous and new excavations, has permitted to adapt the investigation to the local characteristics of the site. Moreover, detailed analysis and lateral correlation of anomalies have shown the potential application of the presented methodological approach for this kind of archaeological site.

The analysis, interpretation and survey routine presented can be of interest for the characterization of archaeological sites that do not include monumental architectures but can be more representative of the actual life of inhabitants.

\section{Acknowledgements}

This research has been financed by the Aragón Government (Geotransfer research group) and Centro de Estudios Turiasonenses (Fernando el Católico Institution, Zaragoza). The authors want to acknowledge comments, suggestions and advice from Larry Conyers and Chris Gaffney as editors and two anonymous reviewers.

\section{References}

Abbas AM, Khalil M, Massoud U, et al. 2012. The implementation of multi-task geophysical survey to locate Cleopatra Tomb at Tap-Osiris Magna, Borg El-Arab, Alexandria, Egypt 'Phase II'. NRIAG Journal of Astronomy and Geophysics 1: 1-11.

Aitken M. 1974. Physics and Archaeology, 2nd edn. Clarendon Press: Oxford.

Apostolopoulos G. 2014. Combined geophysical investigation for the detection of ancient metallurgical installations near Keratea City, Greece. Journal of Applied Geophyiscs 104: 17-25.

Argote DL, Tejero A, Chávez RE, López PA, Bravo R. 2000. 3D modelling of magnetic data from an archaeological site in north-western Tlaxcala state, Mexico. Journal of Archaeological Science 36: 1661-1671.

Bagaloni V, Perdomo S, Ainchil J. 2011. Geoelectric and magnetic surveys at La Libertad archaeological site (San Cayetano County, Buenos Aires Province, Argentina): a transdisciplinary approach. Quaternary International 245: 13-24.

Batayneh A, Al-Zoubi A, Tobasi U, Haddadin G. 2001. Evaluation of archaeological site potential on the Tall al-Kharrar area (Jordan) using magnetic and electrical resistivity methods. Environmental Geology 41: 54-61.

Belshe J. 1957. Recent magnetic investigations at Cambridge University. Advances in Physics 6: 192-193.

Bevan B. 1983. Electromagnetics for mapping buried earth features. Journal of Field Archaeology 10: 47-54.

Bona López IJ, Albuixech AI, Núñez Marcén J. 1989. 'La Dehesa (Tarazona'. In El Moncayo. Diez años de investigación arqueológica y prólogo de una labor de futuro, Bona López IJ et al. (eds). Centro de Estudios Turiasonenses: Tarazona; 117-118.

Caggiani M, Cimnale M, Gallo D, Noviello M, Salvemini F. 2012. Online non destructive archaeology: the archaeological park of Egnazia (southern Italy) study case. Journal of Archaeological Science 39: 67-75.

Clark AJ. 1996. Seeing Beneath the Soil. Prospecting Methods in Archaeology. B.T. Batsford Ltd: London.

Conyers LB. 2004. Ground-penetrating Radar for Archaeology. Alta Mira Press: Walnut Creek, CA; 203 pp.

Conyers LB. 2012. Interpreting Ground-penetrating Radar for Archaeology. Left Coast Press: Walnut Creek, CA.

Conyers LB. 2013. Ground-penetrating Radar for Archaeology. Alta Mira Press: Walnut Creek, CA; 258 pp.

De Smedt P, Saey T, Lehouck A, et al. 2013. Exploring the potential of multi-receiver EM1 survey for geoachaeological prospection: a 90 ha dataset. Geoderma 199: 30-36. 
De Smedt P, Van Meirvenne M, Saey T, Baldwin E, Gaffney C, Gaffney C. 2014. Unravelling the prehistoric landscape at Stonehenge through multi-receiver EMI. Journal of Archaeological Sciences 50: 16-23.

Drahor MG. 2006. Integrated geophysical studies in the upper part of Sardis archaeological site, Turkey. Journal of Applied Geophysics 59: 205-223.

Drahor MG. 2011. A review of integrated geophysical investigations from archaeological and cultural sites under encroaching urbanisation in Izmir, Turkey. Physics and Chemistry of the Earth 36: 1294-1309.

Drahor MG, Berge MA, Kurtulmus TÖ, Hartmann M, Speidel MA. 2008a. Magnetic and electrical resistivity tomography. Investigations in a Roman legionary camp site (Legio IV Scythica) in Zeugma, southeastern Anatolia, Turkey. Archaeological Prospection 15: 159-186.

Drahor MG, Kurtulmus TÖ, Berge MA, Hartmann M, Speidel MA. 2008b. Magnetic imaging and electrical resistivity tomography studies in a Roman Military installation found in Satala archaeological site from northeastern of Anatolia, Turkey. Journal of Archaeological Science 35: 259-271.

Eppelbaum LV, Khesin BE, Itkis SE. 2010. Archaeological geophysics in arid environments: examples from Israel. Journal of Arid Environments 74: 849-860.

Ernenwein E, Hargrave M. 2009. Archaeological Geophysics for DoD Field Use: a Guide for New and Novice Users, Report. US Army Corps of Engineers: Washington, DC; 109 pp.

Forte E, Pipan M. 2008. Integrated seismic tomography and ground-penetrating radar (GPR) for the highresolution study of burial mounds (tumuli). Journal of Archaeological Science 35: 2614-2623.

Gaffney C, Gater J. 2003. Revealing the Buried Past: Geophysics for Archaeologists. Tempus Publishing: Stroud.

Gaffney V, Patterson H, Piro S, Goodman D, Nishimura Y. 2004. Multimethodological approach to study and characterize Forum Novum (Vescovio, Central Italy). Archaeological Prospection 11: 201-212.

García Serrano JA. 2003. Arqueología del Moncayo. Catálogo de la exposición permanente. Centro de Estudios Turiasonenses: Tarazona; 122-123: 150-151.

Hesse A. 1999. Multi-parametric survey for archaeology: how and why, or how and why not? Journal of Applied Geophysics 41: 157-168.

Hesse A, Jolivet A, Tabbagh A. 1986. New prospects in shallow depth electrical surveying for archaeological and pedological applications. Geophysics 51: 585-594.

Huang H. 2005. Depth of investigation for small broadband electromagnetic sensors. Geophysics 70(6): G135-G142.

Huang H, Won JJ. 2000. Conductivity and susceptibility mapping using broadband electromagnetic sensors. Journal of Environmental and Engineering Geophysics 5: 31-41.

Lasaponara R, Luecci G, Masini N, Persico R. 2014. Investigating archaeological looting using satellite images and georadar: the experience in Lambayaque in north Peru. Journal of Archaeological Science 42: 216-230.

Linington R. 1966. Test use of a gravimeter on Etruscan chamber tombs at Cerveteri. Prospezioni Archeologiche 1: 37-41.

Neubauer W, Eder-Hinterleitner A. 1997. Resistivity and magnetics of the Roman town Carnuntum, Austria: an example of combined interpretation of prospection data. Archaeological Prospection 4: 179-189.
Özgü Arısoy M, Özdemir K, Büyüksaraç A, Bilim F. 2007. Images of buried graves in Bayat, Afyon (Turkey) from high-resolution magnetic data and their comparison with preliminary excavations. Journal of Archaeological Science 34(I): 1473-1484.

Papadopoulos NG, Sarris A, Salvi MC, Dederix S, Soupios P, Dikmen U. 2002. Rediscovering the small theatre and amphitheatre of ancient lerapytna (SE Crete) by integrated geophysical methods. Journal of Archaeological Science 39: 1960-1973.

Pellerin L. 2002. Application of electrical and electromagnetic methods for environmental and geotechnical investigations. Surveys in Geophysics 23: 101-132.

Quirantes J. 1978. Estudio sedimentológico y estratigráfico del Terciario Continental de Los Monegros. Publicación Institución Fernando el Católico: Zaragoza; 208.

Rego HP, Cegielski WH. 2014. Gradiometry survey and magnetic anomaly testing of Castros de Neixón, Galicia, Spain. Journal of Archaeological Science 46: 417-427.

Rogers MB, Faehndrich K, Roth B, Shear G. 2011. Cesium magnetometer surveys at a Pithouse Site near Silver City, New Mexico. Journal of Archaeological Science 37: 1102-1109.

Sanz Núñez AC. 1982. Métodos geofísicos aplicados a la prospección arqueológica. Toriaso III: 9-27:

Scollar I. 1962. Electromagnetic prospecting methods in archaeology. Archaeometry 5: 146-153.

Seren S, Eder-Hinterleitner A, Neubauer W, Groh S. 2004. Combined high resolution magnetics and GPR surveys of the roman town of Flavia Solva. Near Surface Geophysics 2: 63-68.

Shaaban FF, Shaaban FA. 2001. Use of two-dimensional electric resistivity and ground penetrating radar for archaeological prospecting of the ancient capital of Egypt. African Earth Sciences 33: 661-671.

Sternberg K, McGill JW. 1995. Archaeology studies in southern Arizona using ground penetrating radar. Journal of Applied Geophysics 33: 209-225.

Tsokas GN, Giannopoulos A, Tsourlos P, et al. 1994. A large scale geophysical survey in the archaeological site of Europos (N. Greece). Journal of Applied Geophysics 32: 85-98.

Tsokas GN, Hansen RO. 2000. On the use of complex attributes and the inferred source parameter estimates in the exploration of archaeological sites. Archaeological Prospection 7: 17-30.

Urban TM, Rowan YM, Kersel MM. 2014. Groundpenetrating radar investigations at Marj Rabba, a Chalcholithic site in the lower Galilee of Israel. Journal of Archaeological Science 46: 96-106.

Vaughan CJ. 1986. Ground penetrating radar surveys used in archaeological investigations. Geophysics 51: 595-604.

Witten A. 2006. Handbook of Geophysics and Archaeology. Equinox Publishing Ltd: London.

Witten A, Calvert G, Witten B, Levy T. 2003. Magnetic and electromagnetic induction studies at archaeological sites in southwestern Jordan. IEEG 8: 209-215.

Witten AJ, Levy TE, Adams RB, Won LJ. 2000. Geophysical surveys in the Jebel Hamrat Fidan, Jordan. Geoarchaeology 15(2): 135-150.

Zheng W, Li X, Lam N, et al. 2013. Applications of integrated geophysical method in archaeological surveys of the ancient Shu ruins. Journal of Archaeological Science 40: $166-175$. 